\title{
NOŚNOŚĆ PODSTAW SŁUPÓW Z RUR OKRĄGEYCH ZGINANYCH I ŚCISKANYCH
}

\begin{abstract}
Obliczanie nośności i sztywności podstaw słupów ujęto w Eurokodach jedynie w odniesieniu do słupów o trzonach wykonanych $\mathrm{z}$ dwuteowników walcowanych lub ich spawanych odpowiedników. W praktyce inżynierskiej często stosowane są słupy o trzonach z kształtowników zamkniętych wewnątrz pustych: kołowych lub prostokątnych. Obliczanie ich nośności i sztywności powinno także odbywać się z zastosowaniem metody składnikowej. W artykule przedstawiono zasady kształtowania konstrukcyjnego oraz propozycję obliczania nośności podstaw słupów z rur okrągłych, zginanych i ściskanych. W proponowanej metodzie rozpatrzono następujące składniki: blachę podstawy przy zginaniu w strefie docisku, blachę podstawy przy zginaniu w strefie rozciągania oraz śruby kotwiące w strefie rozciągania. Podaną procedurę projektową zilustrowano przykładem obliczeniowym.
\end{abstract}

Słowa kluczowe: konstrukcje stalowe, metoda składnikowa, podstawy słupów, rury okrągłe

\section{Wstęp}

Słupy o trzonach z rur okrągłych są projektowane przede wszystkim jako wolnostojące elementy utwierdzone w fundamentach, obciążone głównie momentem zginającym (konstrukcje wsporcze reklam, sygnalizacji, zbiorników itp.) lub siłą osiową (podpory pawilonów i budynków kilkukondygnacyjnych).

Zagadnienia dotyczące projektowania podstaw słupów zarówno od strony kształtowania elementów, jak też ich obliczania w stanie sprężystym są wystarczająco przedstawione w piśmiennictwie, np. [1] do [4]. W normach europejskich dotyczących projektowania konstrukcji stalowych [6], [7] zagadnienia

\footnotetext{
${ }^{1}$ Autor do korespondencji/corresponding author: Jan Bródka, jan.brodka@gmail.com

2 Agnieszka Głuszko, Politechnika Rzeszowska, agluszko@prz.edu.pl

${ }^{3}$ Marcin Górski, Politechnika Rzeszowska, mgorski@prz.edu.pl

${ }^{4}$ Aleksander Kozłowski, Politechnika Rzeszowska, kozlowsk@prz.edu.pl
} 
odnoszące się do podstaw słupów z rur okrągłych nie zostały ujęte. Istnieje pokaźne piśmiennictwo zagraniczne (np. [5], [8]), odnoszące się do podstaw słupów jako węzłów podatnych, jednak zwykle przedstawiające zagadnienia w ujęciu słupów z dwuteowników.

\section{Kształtowanie podstaw słupów z rur okrągłych}

Na rys. 1 pokazano dwa podstawowe przykłady blach poziomych podstaw słupów z rur okrągłych. Zwykle podstawa jest kwadratowa, a cztery śruby kotwiące są rozmieszczone $w$ jej narożach (rys. 1a). Taki kształt i rozmieszczenie kotew jest przyjmowany wtedy, kiedy słup przenosi głównie zginanie. Jeżeli siła podłużna powoduje wzrost wytężenia w słupie, to zwykle projektuje się blachę poziomą podstawy w kształcie sześcioboku foremnego (rys 1b). W wypadku działania na trzon dużych momentów zginających, powodujących stosowanie rur o dużych średnicach projektuje się okrągłe, poziome blachy podstawy. W takiej sytuacji projektowej wzrasta liczba śrub kotwiących i wtedy ocenę nośności należy rozwiązywać tak, jak to czyni się w wypadku kominów [4].

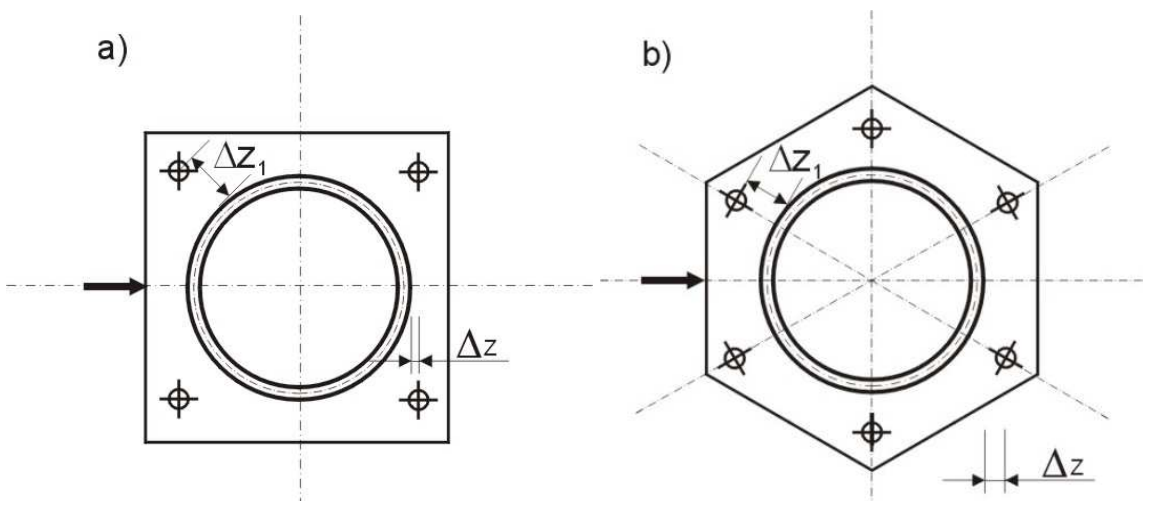

Rys. 1. Przykładowa geometria blach poziomych podstaw słupów okrągłych

Fig. 1. Sample geometry of base plates of CHS columns

\section{Ocena nośności podstawy słupa w strefie ściskanej}

W [7] oceny nośności strefy ściskanej dokonuje się, ustalając wysięg będący częścią blachy podstawy, odmierzany od zewnętrznego i wewnętrznego brzegu ścianki trzonu kształtownika zamkniętego. Aby ustalić ramię dźwigni (odstęp między wypadkową strefy docisku a osią śruby kotwiącej), należy określić zasięg strefy ściskanej dla przypadku ściskania mimośrodowego (pole zacienione na rys. 2). 

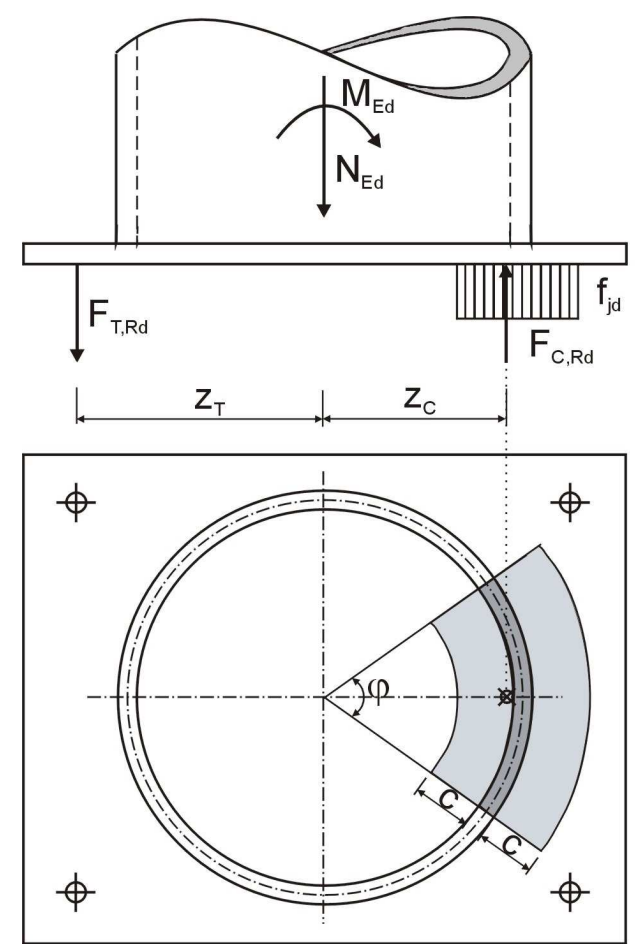

Rys. 2. Rozkład sił w połączeniu oraz zasięg strefy ściskanej

Fig. 2. Distribution of forces in connection and range of compression zone

Strefa ściskana bierze udział w przenoszeniu momentu zginającego oraz siły podłużnej, a w przypadku obciążenia osiowego słupa jej zasięg obejmuje cały przekrój. Geometrię strefy ściskanej ustala się następująco (rys. 3):

$$
z_{C}=\frac{r_{c} \cdot b_{c}}{s_{c}} \quad s_{C}=\frac{\pi \cdot r_{c} \cdot \varphi}{180^{\circ}} \quad b_{C}=2 \cdot r_{c} \cdot \sin \frac{\varphi}{2}
$$

przy czym:

$z_{C}$ - odległość środka ciężkości strefy ściskanej od środka ciężkości przekroju rury okrągłej,

$s_{c}-$ długość łuku w strefie ściskanej,

$b_{c}$ - rozpiętość łuku tej strefy, mierzona między jej końcami w osi jej przekroju,

$r_{C}=\frac{d-t}{2}-$ promień łuku tej strefy, mierzony w osi jej przekroju,

$d$ - zewnętrzna średnica zastosowanej rury,

$t$ - grubość ścianki rury,

$\varphi$ - kąt wycinka strefy ściskanej, zawarty między promieniami łuku tej strefy, wskazującymi jej końce, przyjmowany w stopniach. 


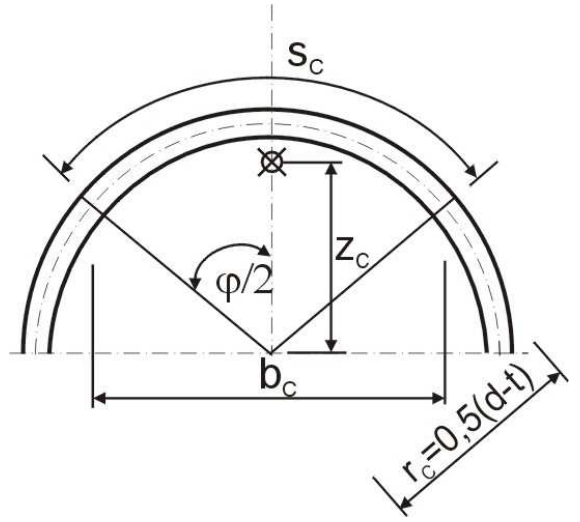

Rys. 3. Geometria strefy ściskanej

Fig. 3. Geometry of compression zone

Obciążenie części ściskanej i rozciąganej podstawy trzonu słupa ustala się jako:

$$
F_{C f}=\frac{N_{E d}}{2}+\frac{M_{E d}}{z} ; F_{T f}=\frac{N_{E d}}{2}-\frac{M_{E d}}{z} ; z=z_{C}+z_{T}
$$

gdzie:

$N_{E d}$ - siła podłużna w trzonie słupa,

$M_{E d}$ - moment zginający trzon słupa,

$z$-ramię dźwigni,

$z_{T}$ - odstęp osi śrub kotwiących od środka ciężkości trzonu słupa.

Układ równań (2), służący do oceny obciążenia stref ściskanej i rozciąganej trzonu słupa, a zarazem blachy poziomej jego podstawy, nie umożliwia uzyskania wartości jednoznacznych. Aby temu zaradzić należy jedno z tych obciążeń przyjąć o wartości ustalonej. Proponuje się, aby tym obciążeniem była wartość:

$$
F_{C f}=\frac{N_{E d}}{2}+\frac{M_{E d}}{z}=F_{C, R d}
$$

Jest to siła, jaką trzon słupa przekazuje w strefie ściskanej, a zarazem nośność tej strefy podczas ściskania podstawy. Ustala się ją, w sposób następujący:

$$
F_{C, R d}=\frac{t \cdot s_{c} \cdot f_{y}}{\gamma_{M 0}}
$$

przy czym: $f_{y}$ - granica plastyczności rury słupa,

Przyjmując wstępnie wartość $\varphi$, ustala się kolejno wartości $F_{C, R d}, z_{C}$ oraz $z$, a następnie metodą kolejnych przybliżeń wyznacza wartość $F_{C f}$ i porównuje z $F_{C, R d}$. Iterację kończy się wtedy, kiedy różnica między porównywanymi wartościami jest minimalna. W omawianej procedurze ściskanie jest dodatnią, a rozciąganie ujemną wartością. 
W [7] pole docisku strefy ściskanej poziomej blachy podstawy do fundamentu po ustaleniu wysięgu $c$ określa się, korzystając z jej współpracujących długości $l_{\text {eff }}$ i szerokości $b_{\text {eff. }}$ Krzywizna tych stref w wypadku rur okrągłych powoduje konieczność rozpatrywania rur grubościennych, ustalając pola docisku w sposób następujący:

$$
A_{c, r e d}^{\prime}=\frac{\pi \cdot\left(r_{0}^{2}-r_{i}^{2}\right) \cdot \varphi}{360^{\circ}}
$$

przy czym:

$$
\begin{aligned}
& r_{0}=\frac{d+2 c}{2}-\text { zewnętrzny promień pola docisku, } \\
& r_{i}=\frac{d-2(t+c)}{2}-\text { wewnętrzny promień pola docisku, }
\end{aligned}
$$

$c$ - wysięg ustalany wzorem (6.5), podanym w [7],

Ustalenie wartości $F_{C f}=F_{C, R d}$ jest zarazem sprawdzeniem nośności strefy ściskanej trzonu słupa. Natomiast oceny nośności poziomej blachy podstawy oraz betonu i podlewki przy docisku dokonuje się następująco:

$$
\frac{F_{c f}}{A_{c, \text { red }}^{\prime}} \leq f_{j d}
$$

przy czym $f_{j d}$ jest obliczeniową wytrzymałością połączenia na docisk (patrz punkt 6.2.5(7) w [7]).

\section{Ocena nośności podstawy słupa}

Zgodnie z metodą składnikową przyjętą w [7], sprawdzenie nośności podstawy słupa przeprowadza się, jak następuje:

$$
\frac{M_{E d}}{M_{R d}} \leq 1,0
$$

gdzie:

$$
M_{R d}=F_{C, R d} \cdot z_{C}+F_{T, R d} \cdot z_{T}
$$

$F_{T, R d}$ - nośność części rozciąganej połączenia, określana na podstawie Tablicy 6.2 zawartej w [7].

\section{Przykład obliczeniowy}

Sprawdzenie nośności podstawy słupa (rys. 4) o przekroju zamkniętym okrągłym $\varnothing 273 \times 14,2$. Wymiary blachy podstawy wstępnie przyjęto $480 \times 460 \times 45$. Obciążenia działające na podstawę słupa: $\mathrm{N}_{\mathrm{Ed}}=70,3 \mathrm{kN}, \mathrm{M}_{\mathrm{Ed}}=160,3 \mathrm{kNm}$. 


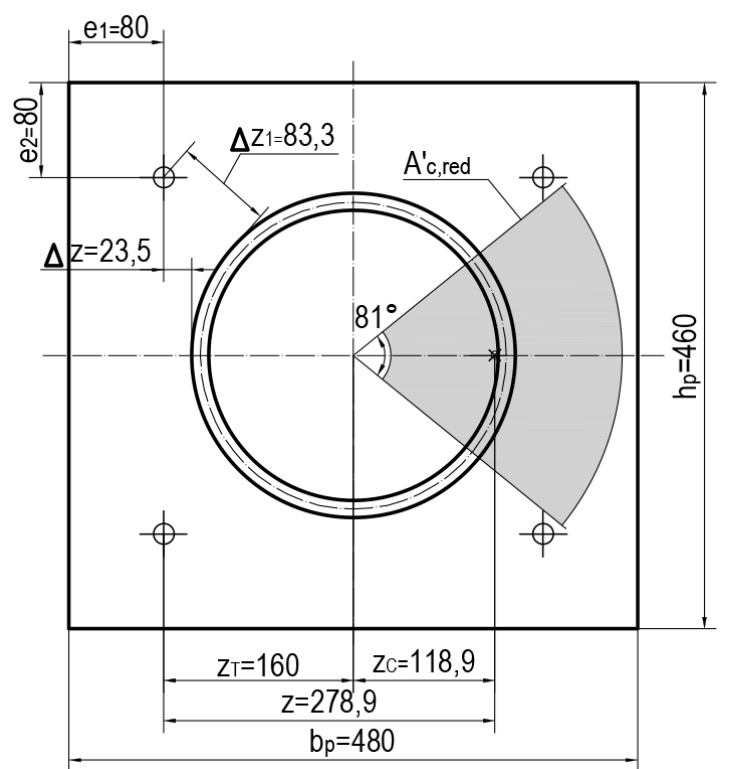

Rys. 4. Geometria analizowanej podstawy słupa

Fig. 4. Geometry of analyzed column base

Dane materiałowe:

- stal S235: $f_{y}=215 \mathrm{~N} / \mathrm{mm}^{2}$ (przy grubości $>40 \mathrm{~mm}$ ), $f_{u}=360 \mathrm{~N} / \mathrm{mm}^{2}$,

- beton C25/30: $f_{c k}=25 \mathrm{~N} / \mathrm{mm}^{2}, \quad f_{c t k}=1,8 \mathrm{~N} / \mathrm{mm}^{2}$,

Przyjęto płytkowe śruby kotwiące M42 ze stali S355:

$$
A_{s}=1120 \mathrm{~mm}^{2} \quad f_{y}=355 \mathrm{~N} / \mathrm{mm}^{2} \quad f_{u}=490 \mathrm{~N} / \mathrm{mm}^{2}
$$

Wyznaczenie położenia środka ciężkości strefy ściskanej $z_{C}$ uzyskuje się w kolejnych krokach iteracji. Przyjęto wstępnie kąt $\varphi=80^{\circ}$.

$$
\begin{aligned}
& s_{c}=\pi \cdot r_{c} \frac{\varphi^{\circ}}{180^{\circ}}=\pi \cdot 129,4 \frac{80^{\circ}}{180^{\circ}}=180,7 \mathrm{~mm} \\
& b_{c}=2 r_{c} \cdot \sin (\varphi / 2)=2 \cdot 129,4 \cdot \sin (80 / 2)=166,4 \mathrm{~mm} \\
& r_{c}=0,5 \cdot(d-t)=0,5 \cdot(273-14,2)=129,4 \mathrm{~mm} \\
& z_{C}=\frac{r_{c} \cdot b_{c}}{s_{c}}=\frac{129,4 \cdot 166,4}{180,7}=119,1 \mathrm{~mm},
\end{aligned}
$$

Obliczono ramię dźwigni z:

$$
\begin{aligned}
& z_{T}=160 \mathrm{~mm} \\
& z=z_{T}+z_{C}=160+119,1=279,1 \mathrm{~mm}
\end{aligned}
$$


Przyjęto $F_{C f}=F_{C, R d}$ i wyznaczono wymaganą wartość ramienia dźwigni z:

$F_{C R d}=t \cdot s_{c} \cdot f_{y} / \gamma_{M 0}=14,2 \cdot 180,7 \cdot 235 / 1,0=602,9 \mathrm{kN}$

$z=\frac{M_{E d}}{F_{C R d}-0,5 N_{E d}}=\frac{160,3 \cdot 10^{6}}{602,9-0,5 \cdot 70,3 \cdot 10^{3}}=282,3 \mathrm{~mm}$

Porównano otrzymane z poczynionych kroków wartości ramienia dźwigni:

$\mathrm{z}=282,3 \mathrm{~mm}>\mathrm{z}=279,1 \mathrm{~mm}$. Wniosek: należy zwiększyć kąt $\varphi$.

Powtórzono poprzednio wykonane kroki, aby zmniejszyć różnicę między wartościami założonego i obliczonego ramienia dźwigni. Ostatecznie przyjęto wartość $\mathrm{z}=278,9 \mathrm{~mm}$.

$$
s_{c}=183 \mathrm{~mm} \quad \varphi_{n}=81^{\circ} \quad b_{c}=167,8 \mathrm{~mm} \quad z_{C}=118,9 \mathrm{~mm} \quad z_{T}=160 \mathrm{~mm}
$$

Nośność strefy ściskanej:

Obliczono siłę ściskającą styk:

$$
\begin{aligned}
& F_{C f}=\frac{N_{E d}}{2}+\frac{M_{E d}}{z}=\frac{70,3 \cdot 10^{3}}{2}+\frac{160,3 \cdot 10^{6}}{278,9}=609,9 \mathrm{kN} \\
& f_{j d}=f_{c d}=\frac{f_{c k}}{\gamma_{c}}=\frac{25}{1,4}=17,8 \mathrm{~N} / \mathrm{mm}^{2} \\
& c=45 \cdot \sqrt{\frac{215}{3 \cdot 17,8 \cdot 1,0}}=90,3 \mathrm{~mm} \\
& r_{0}=(d+2 c) / 2=(273+2 \cdot 30,3) / 2=226,8 \mathrm{~mm} \\
& r_{i}=(d-2(t+c)) / 2=(273-2(14,2+90,3)) / 2=32 \mathrm{~mm} \\
& A_{c, \text { red }}^{\prime}=\pi\left(r_{0}{ }^{2}-r_{i}^{2}\right) \frac{\varphi}{360^{\circ}}=\pi\left(226,8^{2}-32^{2}\right) \frac{81^{\circ}}{360^{\circ}}=35620 \mathrm{~mm}^{2} \\
& \frac{F_{C f}}{A_{c, \text { red }}^{\prime}}=\frac{609,9 \cdot 10^{3}}{35620}=16,5 \mathrm{~N} / \mathrm{mm}^{2}<f_{j d}=17,8 \mathrm{~N} / \mathrm{mm}^{2}
\end{aligned}
$$

Nośność ściskanej części połączenia:

$$
\begin{aligned}
& F_{C, R d}=A_{c, r e d}^{\prime} f_{j d}=35620 \cdot 17,8=634 k N \\
& F_{C, R d}=634 k N>F_{c f}=609,9 k N
\end{aligned}
$$

Warunek został spełniony.

Nośność strefy rozciąganej ustalono jako najmniejszą nośność z trzech możliwych modeli zniszczenia króćca teowego (Tablica $6.2 \mathrm{w}$ [7]):

$$
F_{T, R d}=\min \left(F_{T, 1-2, R d} ; F_{T, 3, R d}\right)=\min (626 \mathrm{kN} ; 790,2 \mathrm{kN})=626 \mathrm{kN}
$$

Obliczono siłę rozciągającą styk:

$$
F_{T f}=\frac{N_{E d}}{2}-\frac{M_{E d}}{z}=\frac{70,3 \cdot 10^{3}}{2}-\frac{160,3 \cdot 10^{6}}{278,9}=539,6 \mathrm{kN}
$$


$F_{T, R d}=626 \mathrm{kN}>F_{T f}=539,6 \mathrm{kN}$

Nośność podstawy słupa:

$$
\begin{aligned}
& M_{j, R d}=F_{T, R d} \cdot z_{T}+F_{C, R d} \cdot z_{C}=626 \cdot 0,16+634 \cdot 0,1189=175,5 \mathrm{kNm} \\
& M_{j, R d}=175,5 \mathrm{kNm}>M_{E d}=160,3 \mathrm{kNm}
\end{aligned}
$$

Nośność połączenia jest zapewniona.

\title{
Literatura
}

[1] Bogucki Wł.: Budownictwo stalowe. Arkady. Warszawa.. Część 1, 1976; Część 2, 1977.

[2] Bródka J., Broniewicz M.: Konstrukcje stalowe z rur. Arkady. Warszawa 2000.

[3] Bródka J., Broniewicz M.: Kształtowniki o przekrojach zamkniętych. Poradnik dla projektantów i konstruktorów. Część 1. KoenigStahl. Warszawa 2005.

[4] Bródka J., Kozłowski A., Ligocki I., Łaguna J., Ślęczka L.: Projektowanie i obliczanie połączeń i węzłów konstrukcji stalowych. Drugie wydanie. Tom 1, 2013; Tom 2, 2015. Rzeszów.

[5] Jaspart J.P., Wald F., Weynand K., Gresnigt A., M.: Steel column base classification. - Heron. Vol. 53, no 1/2. Special issue: Steel column bases.

[6] PN-EN 1993-1-1: 2006 Eurokod 3: Projektowanie konstrukcji stalowych - Część 1-1: Reguły ogólne i reguły dla budynków. PKN, Warszawa.

[7] PN-EN 1993-1-8: 2007 Eurokod 3: Projektowanie konstrukcji stalowych - Część 1-8: Projektowanie węzłów. PKN, Warszawa.

[8] Wald F.: Patky sloupů - Column bases. ČVUT. Praha 1995.

\section{MOMENT RESISTANCE OF THE COLUMN BASES OF CIRCULAR HOLLOW CROSS SECTION COLUMN}

\begin{abstract}
S u m m a r y
Eurocodes include design procedures for calculating moment resistance and stiffness of column bases of I-section or their welde d equivalents. In engineering practice very often column of cross section of circular or rectangular hollow section is applied. Estimation of their moment resistance and initial stiffness should be conducted also by component method. Methods of structural shaping and proposal of design procedure for determination of moment resistance of circular hollow section column bases subjected to bending moment and axial force was presented. The following components has been considered: base plate in bending under compression, base plate in bending under tension and anchor bolt in tension. Design procedure was supported by working example.
\end{abstract}

Keywords: steel structures, component method, column bases, hollow section column

Przestano do redakcji: 07.06.2016 $r$.

Przyjęto do druku: 30.06.2016 r.

DOI: $10.7862 / \mathrm{rb} .2016 .39$ 